\title{
Open Label Treatment Epoch
}

National Cancer Institute

\section{Source}

National Cancer Institute. Open Label Treatment Epoch. NCI Thesaurus. Code C102256.

A period in a clinical study during which subjects receive open label therapeutic treatment. 